\title{
A study on effects of demographic variables on success of social media
}

\author{
Marjan Mohammadreza*
}

${ }^{a}$ Master of marketing, Faculty of business and accounting, Allameh Tabataba'i University Tehran, Iran

\begin{tabular}{|c|c|}
\hline A R T I C L E I N F O & AB S T R A C T \\
\hline $\begin{array}{l}\text { Article history: } \\
\text { Received April 28, } 2012 \\
\text { Accepted } 6 \text { July } 2012 \\
\text { Available online } \\
\text { July } 12 \text { 2012 } \\
\text { Keywords: } \\
\text { Social media } \\
\text { Marketing in social media } \\
\text { Success of social media } \\
\text { Demographic variables }\end{array}$ & $\begin{array}{l}\text { In the recent years, social media have developed significantly and their usages have become } \\
\text { main activities of internet users. The proposed study of this paper considers the effects of } \\
\text { personal characteristics such as age, gender and marital status on social media. The study } \\
\text { designs a questionnaire and distributes } 385 \text { questionnaires among students who are enrolled in } \\
\text { different educational levels in governmental university named Allameh Tabatabayi university } \\
\text { located in Tehran, Iran during the year of } 2011 \text {. Because of abnormality of data, non-parametric } \\
\text { test were used. In this research, we studied the effects of demographic variables on success of } \\
\text { social media. The results showed that success of social media is more important among female } \\
\text { students. Marriage situation shows that social media success variable is more important among } \\
\text { married than single ones and, finally, this variable is more important among older people. }\end{array}$ \\
\hline
\end{tabular}

\section{Introduction}

Today's world is severely complex and competitive, and its rapid changes encountered organizations with several challenges. In these conditions, those organizations are successful that use opportunities by managerial tools and modern technology to encourage customers consume more and provide more economic value for their stockholders. In fact, in such circumstances, customers have more choices to select and survival of organizations is more important than ever. Modern communication media provide a suitable background for mutual relationship. Relationship with customers provides an opportunity for organizations to offer their products and services. In addition, they can perceive market's needs better by receiving views of customers.

Social media are suitable tools to maintain a strong relationship between customers and products. Therefore, social media should be able to absorb customers and coordinate them with organization's activities. Thus, marketing managers can use this tool by study of demographic features of addressee group and their view towards social media. As a result, in this study, we intend to study the effects of demographic features of audiences on success of social media to help marketing managers maintain a

* Corresponding author. Tel: +989124020476

E-mail addresses: mmr_bm83@yahoo.com (M. Mohammadreza) 
long-term relationship with their addressees (Liu \& Arnett, 2000). By results of this research, managers understand which group (by sex and old) can be more success in social media. As a result, if they have their desired customers, they can use social media to communicate with them.

\subsection{Social media definition}

Social media refers different activities, practices, and behaviors among communities of people who gather online to share information, knowledge, and opinions using conversational media. Conversational media are Web-based applications, which make it possible to create and easily transmit content in different forms of words, pictures, videos, and audios (Safako \& Brake, 2009).

Social media marketing is any form of direct or indirect marketing used to build awareness, recognition, recall, and action for a brand, business, product, person, or other entity and is carried out using the tools of the social Web, such as blogging, micro blogging, social networking, social bookmarking, and content sharing (Klososky, 2011).

The goal of all social media in a business context is to engage people. Engagement leads towards a desired action or outcome. For an employee, the desired outcome may be a more efficient work process, which reduces a product's time to market. For a customer, the desired outcome may be an additional purchase or a strong recommendation to a friend. In this research, we examine social media from customer point of view (Safko \& Brake, 2009).

\subsection{Different kinds of social media}

\subsubsection{Social Networking}

Many people confuse the terms social networking and social media and they often use one instead of another one while these two terms are completely different and the former is a category of the latter. Social networking tools allow us to share information about our interests with friends, professional colleagues, and others. Most of these tools help us create a profile and post content (text, video, audio, photos) or link different things among various groups of people with common interest. Few people join an online social network because they want to be sold something by someone else in their social network.

\subsubsection{Publish}

Regardless of the business we are in, if we use any web-based application to engage our employees, customers, or prospects, then we are to some degree a publisher. We will quickly discover that the content we present to our target audience will impact how people perceive our company. Publishing is a broad category, which includes tools facilitating e-mail campaigns, blogging, and wikis. There are even tools, which help us manage our online content.

\subsubsection{Photo Sharing}

The ability to archive and share photos may be very valuable to our business. In this category, it is possible to find tools, which help manage photos.

\subsubsection{Audio}

These days, iPod, one of APPLE's company's product, has become ubiquitous in society. The ability to download and carry thousands of hours of songs, podcasts, and other programs on a device that slips into a shirt pocket is truly amazing. Many college students now get recordings (podcasts) of their professors' lectures to play back later. Some company CEOs send out monthly messages to their workers via a podcast. Thanks to a group of dedicated podcasters, it is now possible to take selfguided tours of several museums by downloading an audio tour without leaving home. Indeed, audio 
appeals to people on the go, and it has certain advantages over text-based tools and even video. It's unlikely to go and read something or view video while a person is jogging, but audio is the perfect companion.

\subsubsection{Video}

If a picture is worth a thousand words, what is the value of video? This is an important category because most of us have been raised with at least one television at home. News, sports, entertainment, even infomercials have entered our lives on the television screen. That same content can now be viewed on computer or on mobile phone.

\subsubsection{Microblogging}

This is another tool for communicating something important or meaningful in less than 140 characters.

\subsubsection{Livecasting}

This category encompasses internet radio and other applications, which allows us to stream a live broadcast to an audience or social network. Livecasting offers a flexible means of engaging audiences by educating or entertaining them.

\subsubsection{Virtual Worlds}

If for whatever reason one wishes to become an incarnation of someone or something else, then a virtual world may be worth considering. There is no need to go to extremes, however, to assume a persona and become part of a computer-generated world where one can interact with others in a virtual community.

\subsubsection{Gaming}

Gaming and virtual worlds have some things in common, but what separates them apart is the notion of cooperation and competition that is the very basis of gaming. Gamers are part of a fiercely loyal kind of online community. They spend hours playing in environments where conversation and shared experiences with other players across time zones and even continents is common. Not surprisingly, many game manufacturers now offer product placement and advertising opportunities in their games.

\subsubsection{Productivity Applications}

This is a bit of a catch-all category, but the common denominator to all of the tools that live here is that they enhance business productivity in one way or another. Unlike many tools in the social media ecosystem created for the millennial generation's propensity to share the intimate details of their lives with friends and cohorts, tools in this category are serious business applications.

\subsubsection{Aggregators}

Tools in this category help gather, update, and store information for easy access. Additionally, some aggregators leverage the wisdom of the crowd and tell us what other people are saying about a particular product, service, or brand. These can be excellent tools for capturing market intelligence.

\subsubsection{RSS}

RSS is an acronym for Rich Site Summary. A lot of web content changes. The tools in this category automatically feed you current content from the web sites that are most critical to your business needs. It could be an industry blog, statistics posted on a competitor's site, or information from a government agency's web site. 


\subsubsection{3, Search}

In just a few years, Google has become synonymous with doing an Internet search. If people use tools like Google to find people, places, and things that are interesting, essential, or desirable and they have a relevant product or service, then they need to know something about the tools in this category.

\subsubsection{Mobile}

Mobile phones are quickly becoming the most important appliance we can own. In fact, many of the tools from other categories in the social media ecosystem can be accessed via your mobile phone, and yet there are specific tools that make your mobile phone a more powerful business ally. This category focuses on these tools.

\subsubsection{Interpersonal}

Tools in this category facilitate people-to-people communication and collaboration. To stalwart social media aficionados, many of these tools do not belong in the social media ecosystem, but if we are in the business of managing people, processes, or products, we need to be aware of these tools (Safako \& Brake,2009).

\subsection{The four pillars of social media marketing}

For success in social media marketing, we must review the four pillars of social media marketing and commit to including all four in our social media marketing activities at all times.

\subsubsection{Pillar One: Read}

A successful social media marketing plan begins with research, and that research must be ongoing. In simplest terms, social media marketing requires a lot of reading. Not only must we stay current on what's going on in our industry, but we also need to be aware of the ongoing online conversations happening related to our industry, business, products, services, customers, and competitors. The best social media marketers are well versed on their industries, competitors, customers, trends, and all other topics related to their businesses. (Mangold, \& Faulds, 2009). The first step to develop social media marketing plan is have one or more of the items such as websites, news sites, press releases, Blogs, E-books, periodicals (online and offline), online videos published by individuals or groups related to our industry, Podcasts and online radio shows produced by individuals or groups related to our industry and finally printed newspapers and periodicals (Kaplan, \& Haenlein, 2010).

\subsubsection{Pillar Two: Create}

Most social media experts suggest that creating great content is the most important part of any social media marketing plan. Success in social media marketing comes from developing online conversations about the business, brand, products, and promotions. It's hard to start those conversations, sustain them, and motivate others to share them. Keep in mind, creating amazing content goes deeper than sharing useful snippets such as coupon codes and discount announcements. Amazing content truly adds value to the audience and the online conversation (Perdue, 2010).

\subsubsection{Pillar Three: Share}

A unique aspect of social media marketing is sharing content as a method to indirectly market a business. When most people think about marketing, they think of direct advertising and promotional methods. However, social media marketing adds new elements to the marketing mix based on behaviors related to sharing. In a world that has become somewhat cynical and distrusting of advertising, consumers have come to depend more than ever on relationships, reviews, recommendations, and conversations. You can leverage that desire for sharing information by sharing 
content online. In essence, the social Web brought behavioral targeting to the forefront of marketing strategy after decades of reliance on demographic targeting. Sharing content can come in two primary forms (Anderson, 2008). First, we can share interesting and useful content we find online during our reading (the first pillar). Whether we find a great blog post filled with tips that could help our customers use products like the ones we sell or find a timely online news article that discusses changes coming in our industry, we can share that content online and indirectly boost our social media presence, which in turn indirectly markets our business (Fischer, 2010).

\subsubsection{Pillar Four: Discuss}

As we create and share more and more amazing content, our online audience will grow organically. In time, many members of that audience will become our loyal followers. The more we engage them by creating and sharing amazing content, the more they are likely vocalize their appreciation, thoughts, and opinions (both positive and negative). The final pillar of social media marketing is discussion. When our audience interacts with us by leaving a comment on one of our blog posts, sharing our content, connecting with us via social pages or social networking, and so on, it is essential that we respond to them. No one likes to be ignored, but everyone likes to be acknowledged positively. The power of social media marketing comes from our loyal audience members, who often become our vocal brand advocates and brand guardians. Their collective voices can champion our brand and our messages by sharing our content across the social Web, and they can protect our brand by speaking out against negative and false information. Many of the most popular social media experts claim that their success came primarily from building loyal followings, which started by creating great content but grew because they responded to all comments left on their blogs, social networking interactions, and Twitter interactions. They also answered all e-mails and made themselves accessible to their audiences by showing audience members they were value (Mangold \& Faulds, 2009) .

\section{The proposed study}

In this study, we investigate the effect of personal characteristics such as age, gender and marital status on social activities.

\subsection{Research assumptions}

Success of social media is more important for women than men.

Success of social media is more important for married than single ones.

Importance of success of social media increases by oldness

\section{Related literature}

Johnason (2010) studied a social media and awareness brand. The main point of this research has had the main role of social media in creating awareness from the brand. The question we can ask from this study, is that what in the purpose of using social media to create awareness of the brand? Whatever is important for the company in this stage is to unite attempts of social media with communication strategies. Results of this research was that social media could have an important role to inform brand. The other research was on business to business (B2B) activities in Norway University. In this study, the necessity of using social media in B2B business was considered. The results of this study showed that social media does not change the quality of doing work in trade, but shows the other branch of brand management. It is imperative to communicate with them not to think of selling (Heim, 2010). 


\subsection{Sample size}

Statistical society of this research includes bachelor students of Allameh Tabatabayi University. Cluster random sampling was used to select the sample. First, each faculty was considered as a cluster and different clusters were randomly selected to study students' perspectives. Then the samples were selected by simple systematic random method from different department including Economy, Accounting \& Management, and Rights \& Political Sciences faculties were selected randomly among Economy, Accounting \& Management, Social Sciences, and Rights \& Political Sciences Faculties.

In the sampling method, $\mathrm{k}=5$ was considered. Entrance of this university was observed for 5 successive days for 8:00-18:00. Namely, the first entering student was selected as sample. Then the fifth entering student was selected, and then the tenth. Since the statistical society is not specified and data scale is qualitative, Cochran formula was used to determine the sample volume:

$$
\mathrm{n}=\frac{1.96^{2} \times 0.5 \times 0.5}{0.05^{2}}=384.16 \approx 385
$$

As we can see, the sample volume is nearly equal to 385. Since this is a descriptive-surveying study, questionnaire was used to gather data and they were distributed manually.

\subsubsection{Data analysis method}

After data gathering and study of demographic variables by descriptive statistics, normality test was used to examine social media success variable. Then, non-parametric tests were used to examine the effects of demographic variables.

\subsection{The conceptual model}

There are many studies, which indicate that the success of social media depends on how active users are active (Fawkes, 2001). In social media, active audience must have one of these three characteristics: An active audience must be a member of one of social media of organization. An active audience must actively reply any questions he/she is being asked and an active audience must invite the others in social media of organization (WOM) (Azaroff, 2007).

\section{Research results}

After gathering questionnaires and ranking them, data was examined by descriptive and inferential statistical methods.

\subsection{Descriptive statistics}

In our study, $64.16 \%$ of the participants were male and the remaining $34.81 \%$ were female. In terms of age, $20.2 \%$ of the participant aged between 18 to 20, $29.9 \%$ were between 20 to $22,28.3 \%$ of them were between 22 to 24 and 21.3\% of them were older than 24. In our study, 86\% of the audiences were single and the remaining $11.7 \%$ were married. Finally, $95.7 \%$ of the participants had some experiences on using social media and the remaining $4.3 \%$ did not.

\subsection{Inferential statistical}

- Social media success: The estimation of standard regression coefficients of social media success and its 3 indices are shown in the following table. 


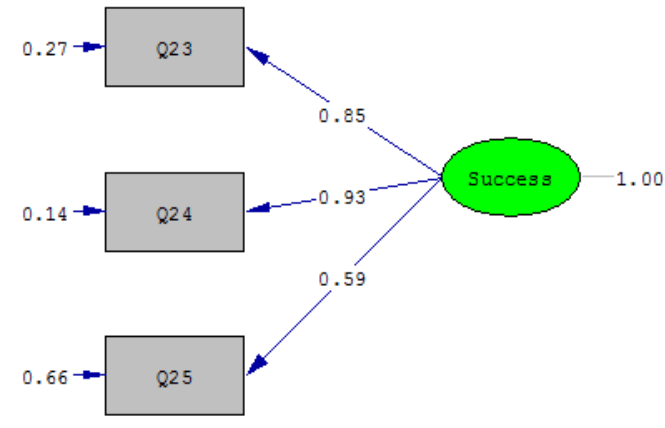

Fig. 1. The estimation of standard regression coefficients of social media success

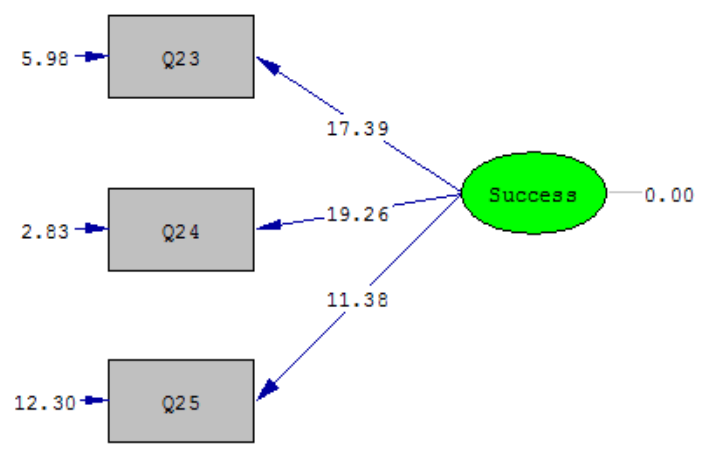

As we can observe from Fig. 1, index 23, which represents membership is associated with social media success with a coefficient of 0.85 and standard error 0.27 . Index 24, which represents the relationship between WOM and media success has a positive coefficient of 0.93 with standard deviation of 0.14. Based on these results, we can conclude that WOM is more associated with social media success. We have considered multiple coefficients of the proposed model of this paper and the results were $0.73,0.86$ and 0.34 for index 23, 24 and index 25, respectively. The value of 0.86 associated with index 24 , for instance, means that $86 \%$ of the changes of dependent variable, social media success, is described by this variable. In addition, Chi-Square for the model is calculated as 13.05, which is located in the critical region when the level of significance is five percent and this means that the null hypothesis is rejected. Fig. 2 shows t-student values for three components, which are all located in the critical region when the level of significance is five percent. Finally, RMSEA is 0.000 , which is another indication of fitness of the model.

To test social media success variable by demographic variables, we first do normality test on social media success variable. According to Kolmogorov-Smirnov test, if significance level is less than 0.05 , normality assumption is rejected, thus the variable does not follow a normal distribution and in our case, for the variable of social media success, Kolmogorov-Smirnov test yields 2.258 with the significance level of 0.000 , which implies that normality assumption can be rejected. In terms of gender characteristics, Kolmogorov-Smirnov test value is 7156.5 with the significance value of 0.000 , which means we can reject the normality assumption when the level of significance is five percent. The median line in Fig. 3 shows that social media success variable is more important for women.

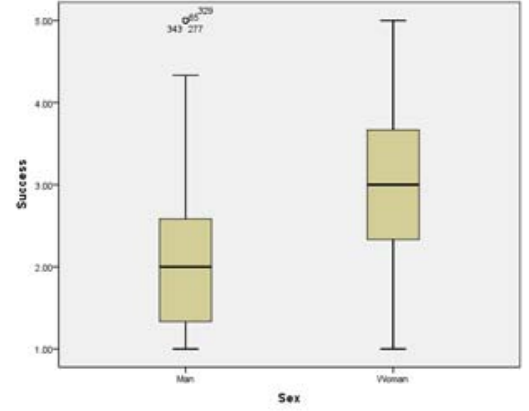

3(a) Gender

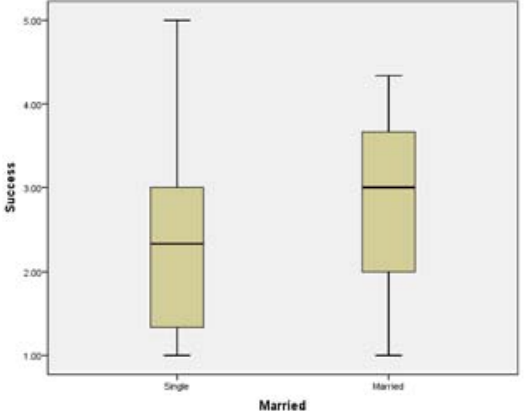

(b) Marital status

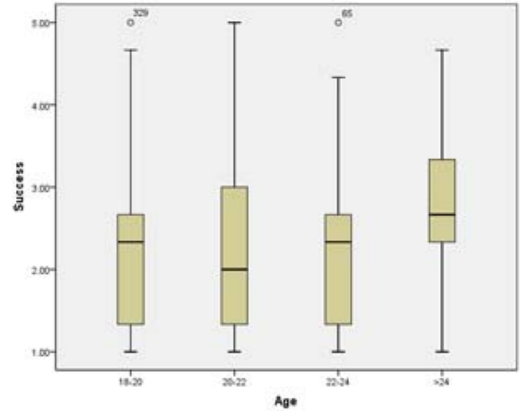

(c) Age

Fig. 3. The effects of gender, marital and age on social media success

The other issue is to study the effect of marital status on social media success and since marital status has two levels of single and married, Mann-whitney non-parametric test has been used to examine the 
effects, which yields 425.4 and the level of significance is 0.001 and, therefore, the null hypothesis is rejected. It means social media success variable is not normally distributed and we should use median line to see the effects. Fig. 4(b) shows the results of median changes and it is clear that married people have shown more rate of success compared with single people. In terms of age, since there are more than two levels, we need to use Kruskal wallis non-parametric test to examine the effect of age on the success of social media. The results of this test yields 24.181 with three degree of freedom and the level of significance is 0.000 , which means the null hypothesis is rejected. Therefore, we must use median as a primary indicator of studying the effect of age on the success of social media. According to Fig. 4(c), social media success has different impacts on various groups of people.

\section{Discussions and recommendations}

In this research, we studied the effects of demographic variables on social media success. The results of this survey conclude that social media success is more important for women than men, social media success is more important for married ones and social media success is more important by older people. Since the results showed that social media success is more important for women, this indicates that women spend more time to interact with social media. Therefore, we propose companies whose audiences are women to put social media, besides advertising by other means of media, in their propaganda and interact with their audience better, in order to increase peoples knowledge of social media and encouraged to interact and communicate with social media. This two way interaction enables companies to better understands customers' and market needs, consequently, by offering product tailored to customers' needs, which will increase companies market share and strengthen their brand name. The results showed that social media success is more important for older people. Therefore, we propose, if the audiences are juvenile and they consider factors of succeed of social media, we can create proper social media for our own company and involve them to offer more appropriate products for them. The results showed that social media success more was important for married people than singles. Companies whose main audience are families could use social media in orders to empower interaction and communication with the audiences and involve their audience with social media.

\section{References}

Anderson. S. (2008). Using social networks to market. Rough Notes, 151(2), 114-115.

Azaroff, W. (2007). Key Success Factors for Social Media Project. From: http://www.netbanker.com/2007/08/ key_success_factors_for_social_media_part1.html

Fawkes, J. (2001). What is Public Relations. Rowtledge, New York.

Fischer, E., \& Reuber, A. R. (2010). Social interaction via new social media: (How) can interactions on Twitter affect effectual thinking and behavior? Journal of Business Venturing, 26, 1-18.

Gunelius, S. (2011). 30 - Minute Social Media Marketing. New York: McGraw Hill.

Heim, T. (2010). Social Media in Business to Business Branding (Unpublished master's thesis). Norwegian University of Science and Technology, Norwegian.

Johansson, M. (2010). Social media and brand awareness: A case study in the fast moving consumer goods sector (Unpublished master's thesis). Lulea University, Sweden.

Kaplan, A, \& Haenlein, M. (2010). Users of the world, unite! The challenges and opportunities of Social Media. Business Horizons, 53, 59-68.

Klososky, S. (2011), Manager's Guide to Social Media. New York: McGraw Hill.

Liu, C., \& Arnett, K. (2000). Exploring the factors associated with web site success in the context of electronic commerce. Information and Management, 30(1), 23-34

Mangold, W. G., \& Faulds, D. J. (2009). Social media: The new hybrid element of the promotion mix. Business Horizons, 52(4), 357-365

Perdue, D. J. (2010). Social Media Marketing: Gaining a Competitive Advantage by Reaching the Masses. Master program, Liberty University

Safko, L., \& Brake, D. (2009). The Social Media Bible. New. Jersey: United States of America. 